This article is licensed under the Creative Commons Attribution-NonCommercial 4.0 International License (CC BY-NC) (http://www.karger.com/Services/OpenAccessLicense). Usage and distribution for commercial purposes requires written permission.

\title{
Rare Incidence of Acute Liver Injury with Potassium Para-Aminobenzoate Introduction
}

\author{
Layth Al Attar Wiliam Kilgore \\ University of Kansas School of Medicine - Wichita, Wichita, KS, USA
}

\section{Keywords}

Hepatology $\cdot$ Potassium para-aminobenzoate $\cdot$ Hepatotoxicity

\begin{abstract}
Acute liver injury is an alarming condition, as it may lead to a devastating outcome. Of the many causes of acute liver injury, review of medications is crucial to identifying the cause of the injury. Some commonly used medications may unpredictably be the underlying cause of liver injury. We present a case of Peyronie's disease treated with potassium para-aminobenzoate that developed acute liver injury. After starting the new treatment, the patient complained of right upper quadrant pain. He was found to have elevated liver enzymes. The condition resolved after stopping potassium para-aminobenzoate use. We report a potassium para-aminobenzoate side effect of liver injury that can be managed conservatively.

$$
\begin{aligned}
& \text { (C) } 2018 \text { The Author(s) } \\
& \text { Published by S. Karger AG, Basel }
\end{aligned}
$$
\end{abstract}




\section{Case Reports in Gastroenterology}

Case Rep Gastroenterol 2018;12:230-233

DOI: $10.1159 / 000488976$

(c) 2018 The Author(s). Published by S. Karger AG, Basel www.karger.com/crg

Al Attar and Kilgore: Rare Incidence of Acute Liver Injury with Potassium Para-Aminobenzoate Introduction

\section{Background}

Peyronie's disease is fibrosis of the tunica albuginea of the penis which causes penile curvature [1]. It is caused by a localized fibrotic disorder of the tunica albuginea. This condition is managed with potassium para-aminobenzoate (PABA), an antifibrotic agent. It increases tissue levels of monoamine oxidase, which decreases levels of serotonin contributing to scar formation. There are few recognized contraindications to this medication, and it has few side effects. The most commonly reported side effects include anorexia, nausea, fever, and rash. Gastrointestinal side effects are the leading cause of poor tolerability [2]. Acute hepatic injury due to PABA is uncommon if not rare [3]. Hepatic injury was documented in 6 cases [4].

\section{Case Report}

A 58-year-old male patient saw his primary care physician for epigastric and right upper quadrant pain. The pain started suddenly a few days prior to his presentation and worsened over time. Pain was localized, did not radiate, and aggravated with body movement. The patient had nausea without vomiting, subjective fever of more than $100^{\circ} \mathrm{F}$, and dark urine. He denied jaundice, diarrhea, or melena. The patient discontinued simvastatin 5 days before his presentation and continued PABA for a few days before stopping it. He wanted to see if that would resolve his symptoms before seeing a physician.

Initial laboratory workup revealed ALT 1,174 U/L, AST $721 \mathrm{U} / \mathrm{L}$, total bilirubin $1.1 \mathrm{mg} / \mathrm{dL}$, and alkaline phosphate $439 \mathrm{U} / \mathrm{L}$. On abdominal ultrasound, the liver was homogeneous in appearance with no masses and no intrahepatic biliary dilatation.

The patient was referred for a gastroenterology evaluation. Upon questioning, the patient denied a history of alcohol consumption. The patient had no previous elevated liver enzymes. On medication reconciliation, the patient was taking simvastatin for years and PABA was recently introduced. Both medications were discontinued with days in between prior to the initial encounter. The use of simvastatin was recognized as a possible aggravating factor for his symptoms. Liver enzymes increased for a few days on serial liver function tests. They peaked at ALT 1,553 U/L, AST 1,003 U/L, alkaline phosphate $543 \mathrm{U} / \mathrm{L}$, and total bilirubin $1.5 \mathrm{mg} / \mathrm{dL}$. Although results were worsening, the patient improved clinically. The patient's pain subsided in intensity and nausea resolved. Further workup results were as follows: anti-nuclear antibody screen was negative, anti-mitochondrial antibody screen $<0.1 \mathrm{U}$, smooth muscle antibody screen was negative, and Cytomegalovirus screen was negative. Epstein-Barr virus IgG was $750 \mathrm{mg} / \mathrm{dL}$, and the patient confirmed a history of mononucleosis infection. As his clinical complaints resolved, he was followed closely with weekly blood work (Table 1). Liver enzymes returned to baseline, with ALT $22 \mathrm{U} / \mathrm{L}$, AST $22 \mathrm{U} / \mathrm{L}$, alkaline phosphate $90 \mathrm{U} / \mathrm{L}$, and total bilirubin $0.6 \mathrm{mg} / \mathrm{dL}$. Complete resolution took around 40 days from the initial encounter.

\section{Discussion}

The sudden elevation of liver markers in this patient marked acute hepatic injury. He was introduced to PABA, which is the likely cause of the acute hepatic injury. Use of PABA was 
linked to hepatotoxicity in 6 cases reported from 1985 through 2008 [4-7]. Elevation of liver markers occurred 4-8 weeks after starting PABA use. A common finding between reported cases was resolution of liver injury markers after stopping PABA. These clinical observations were not supported by documentation of hepatic injury as adverse effect of PABA. Moreover, a retrospective study found that patients receiving PABA were less likely to have abnormal liver function tests than matched controls [3]. Our patient's condition resolved with liver enzymes returning to baseline. Time to resolution was similar to the previously reported cases [4-7]. A liver biopsy, at the initial acute phase, would have been useful to confirm hepatotoxicity due to PABA use. Biopsy was not performed as the patient's symptoms improved, and liver enzymes trended down.

Reported cases of hepatic injury related to PABA use are scarce. Nevertheless, physicians should be attentive to PABA as a cause of acute liver injury. Clinical presentation and significant liver enzyme elevation are similar to other hepatic injury causes. Medical management is conservative, with discontinuation of PABA and supportive therapy. Complete resolution is achieved without chronic complications reported. In general, liver function testing is not required with PABA therapy initiation. An incidence of therapy complication can be managed conservatively. There should be more focus on increasing awareness among urologists, as they are the primary prescribers of PABA. Alternative therapy, like transdermal verapamil [5], maybe preferred on resuming management.

\section{Statement of Ethics}

Where applicable, the authors confirm that all persons gave their informed consent prior to their inclusion in the study. Details that might disclose the identity of the subjects under study have been omitted.

\section{Disclosure Statement}

The authors have had full access to all the data in the publication (if applicable) and thereby accept full responsibility for the integrity of the data and the accuracy of the data analysis. The authors assert that there are no conflicts of interest (both personal and institutional) regarding specific financial interests that are relevant to the work conducted or reported in this paper.

\section{References}

1 Langston JP, Carson CC 3rd. Peyronie's disease: review and recent advances. Maturitas. 2014 Aug;78(4):341-3.

2 Bella AJ, Perelman MA, Brant WO, Lue TF. Peyronie's disease (CME). J Sex Med. 2007 Nov;4(6):1527-38.

3 Zarafonetis CJ, Dabich L, DeVol EB, Rossi C, Skovronski JJ. Potassium para-aminobenzoate and liver function test findings. J Am Acad Dermatol. 1986 Jul;15(1):144-9.

4 Roy J, Carrier S. Acute hepatitis associated with treatment of Peyronie's disease with potassium paraaminobenzoate (Potaba). J Sex Med. 2008 Dec;5(12):2967-9. 


\section{Case Reports in Gastroenterology}

\begin{tabular}{l|l}
\hline Case Rep Gastroenterol 2018;12:230-233 \\
\hline DOI: 10.1159/000488976 & $\begin{array}{l}\text { @ 2018 The Author(s). Published by S. Karger AG, Basel } \\
\text { www.karger.com/crg }\end{array}$ \\
\hline
\end{tabular}

Al Attar and Kilgore: Rare Incidence of Acute Liver Injury with Potassium Para-Aminobenzoate Introduction

$5 \quad$ Fitch WP 3rd, Easterling WJ, Talbert RL, Bordovsky MJ, Mosier M. Topical verapamil HCl, topical trifluoperazine, and topical magnesium sulfate for the treatment of Peyronie's disease-a placebocontrolled pilot study. J Sex Med. 2007 Mar;4(2):477-84.

6 Borum M, Nsien E, Zimmerman H. Hepatotoxicity from paraaminobenzoic acid. Dig Dis Sci. 1991 Dec;36(12):1793.

7 Mesnil A, Lewden B, Dumortier J, Cuche M, Euvrard P, Dorez D, et al. [Liver injury due to potassium paraaminobenzoate (Potaba)]. Gastroenterol Clin Biol. 2004 Dec;28(12):1295-6. French.

Table 1. Overview of the patient's weekly blood work

\begin{tabular}{lccccrrrr}
\hline & $7 / 24 / 2017$ & $6 / 22 / 2017$ & $6 / 6 / 2017$ & $5 / 30 / 2017$ & $5 / 22 / 2017$ & $5 / 16 / 2017$ & $5 / 11 / 2017$ & $5 / 9 / 2017$ \\
\hline ALT, U/L & 22 & 33 & 120 & 402 & 1,416 & 1,587 & 1,553 & 1,174 \\
AST, U/L & 22 & 32 & 48 & 116 & 345 & 227 & 1,003 & 721 \\
Alkaline phosphatase, U/L & 90 & 113 & 154 & 210 & 392 & 455 & 543 & 439 \\
Total bilirubin, mg/dL & 0.6 & 0.7 & 0.6 & 0.9 & 1.7 & 1.5 & 1.2 & 1.1 \\
Direct bilirubin, mg/dL & 0.3 & 0.4 & 0.3 & 0.4 & 0.9 & 0.8 & 0.8 & \\
\hline
\end{tabular}

